\title{
University fights secrecy ban on computer research
}

A COMPUTER scientist at the University of Wisconsin's Milwaukee campus has been warned by the federal government not to discuss the results of his research with colleagues because to do so might infringe national security regulations.

Dr George I. Davida, associate professor of electrical engineering and computer sciences, has been conducting research for a number of years supported by the National Science Foundation into the security of computer-based data systems. Although the research is unclassified, Dr Davida has now been told by the Department of Commerce, with which he had filed a patent application resulting from his research, that the study "has been found to contain subject matter, the unauthorised disclosure of which might be detrimental to the national security".

The department has added that unauthorised disclosure of the study, which would include discussion of its results with academic colleagues, could be a violation of patent laws. These carry penalties of up to two years in prison and $\$ 10,000$ in fines.

Officials at the university are stunned by the government's action, which they consider to be a serious intrusion of academic freedom, and are seeking legal advice on how to challenge it.

Research into the security of computer-based data systems has become a controversial area in recent years, partly because of concern among officials of the National Security Agency that the open discussion of research results could prejudice their successful application by the federal government.
Last year the agency was accused of harassing scientists working in cryptography during efforts by the National Bureau of Standards to certify a single data encryption standard to be used for all government non-classified information.

An investigation into the NSA's alleged activities was carried out by the Senate Select Committee on Intelligence, which concluded that "there has been no direct or indirect harassment of scientists working in the field of computer security," (a conclusion which will now no doubt be revised).

However, the committee's report added that some NSA officials had expressed concern to the National Science Foundation about certain grants with cryptological ramifications. and suggested that "NSF and NSA should initiate efforts to reduce the ambiguity and uncertainty which surrounds the granting of research funds for public cryptography".

Professor Davida has received two grants from the foundation. The first, which was awarded in 1975, was for a one-year study of cryptographic algorithms for computer data bases. This work involved developing a theory of computation cryptography leading to algorithms for data security having certain required properties (such as resistance to cryptanalysis).

A second grant of $\$ 89,700$ was awarded to Dr Davida last year for a two-year study into the theory and practice of data security. In particular he has been working on models for analysing data-base security in situations where information-system users can sometimes retrieve data they are not authorised to obtain.

Dr Davida submitted a patent application arising from his work in October 1977. As a result of this application, and comments on it received by the Department of Commerce from "a defence agency", he has now been notified from the Patent and Trademark Office that he must not publish the results of his work or discuss it with colleagues. Furthermore any discussions about the research with "foreign nationals" must be officially reported.

Dr Davida would not comment on the affair last week, but issued a statement saying that "because of unanswered legal questions I am unable to discuss a matter of vital concern to me and my colleagues in the academic community." Other computer scientists are surprised the government has reacted so strongly.

Dr Warner A. Baum, chancellor of the University of Wisconsin (Milwaukee) said he was "stunned by the notion that a university professor should get an order from the US government saying that he cannot talk to people about his research". The university does not allow classified research on any of its campuses following bombing of a mathematics building on its Madison campus during anti-Vietnam war demonstrations in 1970.

A spokesman for the NSF said that the foundation had not yet decided whether to join the university in challenging the secrecy order. The case, and its implications for academic freedom, were being given urgent consideration.

David Dickson

\section{Lead levels in Birmingham are typical of urban areas, says UK report}

THE results of recent lead pollution studies in Birmingham have focused attention in the UK on the long-standing controversy over the neurological effects of low lead levels in the body. Although the study found that blood lead levels in its sample of Birmingham people were not unusual for urban dwellers, the almost simultaneous release of the results of studies in Germany and the US, suggesting that even these levels could be responsible for mild neuropsychological disturbance in children, have caused some concern.

This is not the first time Birmingham has been the focus for this debate: four years ago a study of blood and

\section{Spaghetti junction : a clean bill of health}

air lead concentrations in the area around a new motorway interchange in part of the city suburbs aroused some public concern. The latest study, carried out by a joint working party set up by the UK Department of the Environment in the wake of that concern, set out to assess how the presence of the same motorway system at Gravelly Hill, known colloquially as Spaghetti Junction, has affected local lead levels after several years of operation.

The working party found that after the interchange opened, air lead levels near it increased--though not as much as the increase in traffic. It attributes the unexpectedly low increase to the elevated and well-ventilated position of the interchange. However, levels near the junction were found to be higher than those measured at other sites in the city but still below the maximum level currently proposed by the Com- 